\title{
“ADUHAI MALANGNYA PAK KADUK, AYAMNYA MENANG KAMPUNG TERGADAI" SEBAGAI MANIFESTASI KRITIKAN DALAM KANCAH POLITIK TEMPATAN: ANALISIS PRAGMATIK
}

\author{
Muhammad Zaid DAUD*1 \\ Mary Fatimah SUBET ${ }^{2}$ \\ Awang Azman AWANG PAWI ${ }^{3}$ \\ ${ }^{1,2}$ Fakulti Bahasa dan Komunikasi, Universiti Malaysia Sarawak, Sarawak, Malaysia \\ ${ }^{3}$ Jabatan Sosiobudaya, Akademi Pengajian Melayu, Universiti Malaya, Malaysia \\ 1zaid_daud93@yahoo.com \\ ${ }^{2}$ sufatimah@unimas.my \\ 3awangazman@um.edu.my
}

*Corresponding author

\begin{abstract}
ABSTRAK
Kajian ini bertujuan untuk menganalisis baris seloka Pak Kaduk "Aduhai malangnya Pak Kaduk, ayamnya menang kampung tergadai" dengan kancah politik tempatan. Data kajian ini diperoleh melalui antologi Lukisan Zaman oleh Shaari (1991) dan enjin pencarian Facebook (isu semasa berkaitan politik tempatan). Bagi mempertalikan data kajian ini, pengkaji telah menggunakan pendekatan pragmatik: Teori Relevans oleh Sperber dan Wilson (1986). Hasil kajian mendapati bahawa, wujudnya manifestasi kritikan terhadap baris seloka ini seperti, "kritikan terhadap sikap seseorang yang membuat keputusan secara melulu", "kritikan terhadap sikap seseorang yang tidak memikirkan keputusan yang diambilnya akan menyebabkan orang lain terkena tempias" dan "kritikan terhadap golongan atasan menggunakan kuasa atau tipu helah untuk memperdayakan orang bawahan". Rumusannya, manifestasi kritikan terhadap baris seloka ini tidak terhenti pada peringkat permukaannya sahaja, namun maknanya dapat diperluas dalam konteks politik semasa. Kajian ini diharap dapat menjadikan khazanah lisan tinggalan nenek moyang ini sebagai rujukan lanjut dalam memperkatakan perihal suasana politik tempatan semasa. Hal ini dikatakan demikian kerana sejarah sesebuah negara itu juga boleh dirujuk melalui hasil kesusasteraannya.
\end{abstract}

Kata Kunci: Seloka Pak Kaduk; politik tempatan; analisis pragmatik; Teori Relevans 


\title{
"ADUHAI MALANGNYA PAK KADUK, AYAMNYA MENANG KAMPUNG TERGADAI" AS MANIFESTATION OF CRITICISMS IN LOCAL POLITICS: PRAGMATIC ANALYSIS
}

\begin{abstract}
This study aims to analyse Pak Kaduk's seloka line "Aduhai malangnya Pak Kaduk, ayamnya menang kampung tergadai" in local politics scenario. The data of this study is a Malay classical poetry known as seloka Pak Kaduk which is obtained from an anthology entitled "Lukisan Zaman" by Shaari (1991). To further complement the research, data was also taken from Facebook search engine which is confined to current issues related to local politics. To relate the data of this study, the researchers used a pragmatic approach: Relevance Theory by Sperber and Wilson (1986). The research found that, there are manifestations of criticisms of this line such as, "criticism of the attitude of someone who makes reckless decisions", "criticism of a person who does not think about the decisions he make will cause others to suffer" and the "criticism of superiors using power or trickery to deceive subordinates". In conclusion, the manifestation of criticisms of this line of seloka does not end at surface level only, but its meaning can be expanded in the current political context as well. It is hoped that this study can make the valuable oral literature of our ancestors as further reference in discussing the current local political situation as history proved that the history of a nation can as well be referred further by perusing the classical literature' work.
\end{abstract}

Keywords: Seloka Pak Kaduk; current political; pragmatic analysis; Relevance Theory

\section{Pengenalan}

Pak Kaduk (PK) merupakan salah satu watak dalam cerita jenaka Melayu. Watak ini sering dikaitkan dengan sikap yang negatif. Winstedt (1969) telah menyifatkan watak PK sebagai "bodoh-sial". Hal ini dikatakan demikian kerana watak PK digambarkan mempunyai sifat-sifat yang bodoh, tidak menggunakan otak fikirannya dengan waras serta terdorong kepada perasaan yang tamak dan ingin mendapatkan untung (Shaari, 1991). Oleh sebab, sikap sebegini PK telah hilang daya pemikirannya dan akhirnya ditimpa nasib yang malang. Namun begitu, satu penulisan terkini oleh Ismail et al. (2018) telah menyangkal dakwaan Winstedt (1969). Hal ini disebabkan oleh, watak PK tidak hanya merujuk kepada kelakuan negatif. Tetapi, PK turut menjelmakan sifat yang positif seperti "menurut perintah" dan "menepati janji". Menurut Ahmad dan Osman (2007) pula, watak PK yang terakam pada abad ke-19 adalah relevan dengan keadaan sosiopolitik orang Melayu pada abad ke-21. Watak PK sebenarnya terkandung unsur sindiran yang sinis atau tajam untuk ditujukan khas kepada pihak-pihak tertentu (Ahmad \& Osman, 2007). Tambah Shaari (1991), makna implisit yang disajikan dalam naratif PK dapat diperluas kajiannya seperti taktik dan strategi pengarang Melayu dalam menghadapi krisis politik dan pemerintahan semasa. 
Bertitik tolak daripada kenyataan-kenyataan inilah, pengkaji berpendapat perlunya satu kajian alternatif dalam mempertalikan watak PK dengan kancah politik tempatan. Terdapat kajian lepas mengenai watak PK (Ismail et al., 2018; Jabar, 2019; Jabar \& Ghazali, 2021), namun kajian ini lebih menjurus kepada bidang kesusasteraan dan tidak bersifat multidisiplin. Satu teori yang berwibawa diperlukan bagi menganalisis data kajian. Teori Relevans (TR) oleh Sperber dan Wilson (1986) mampu mengatasi ketaksaan makna implisit dalam seloka PK. Makna sebenar yang diinterpretasikan dalam seloka ini dapat membentuk manifestasi kritikan berpandukan konteks politik semasa.

\section{Metodologi Kajian}

Kajian ini adalah berbentuk kualitatif sepenuhnya. Analisis teks dilakukan terhadap seloka PK yang diperoleh daripada antologi Lukisan Zaman oleh Shaari (1986). Pertalian kancah politik tempatan dengan seloka PK pula, diperoleh daripada enjin pencarian Facebook. Keseluruhannya, seloka PK mengandungi 12 baris dan 44 patah perkataan, namun sebagai batasan kajian pengkaji akan menganalisis baris seloka "Aduhai malangnya Pak Kaduk, ayamnya menang kampung tergadai" sahaja. Pensampelan bertujuan dilakukan oleh pengkaji bagi menyaring data berkaitan kancah politik di Malaysia dengan baris seloka PK ini. Analisis pragmatik iaitu TR oleh Sperber dan Wilson (1986) dengan tatacara Subet (2018) dilakukan bagi menganalisis data kajian. Teori ini menekankan konteks, kesan kognitif dan usaha memproses supaya penginterpretasian makna seloka PK dengan kancah politik tempatan lebih mudah, sahih dan berwibawa.

\section{Analisis dan Perbincangan}

Jadual 1 menunjukkan analisis makna eksplikatur sebagai pemahaman awal pembaca.

\section{Jadual 1}

Analisis TR Data "Aduhai malangnya Pak Kaduk, ayamnya menang kampung tergadai"

\begin{tabular}{ll}
\hline Analisis TR \\
\hline Eksplikatur: Aduhai malangnya Pak & Bentuk logik: \\
Kaduk, ayamnya menang kampung & ayam - bentuk tubuhnya seakan-akan \\
tergadai & burung tetapi tidak boleh terbang; nya - \\
& kata ganti nama diri orang ketiga; menang \\
& - berjaya dalam perlawanan atau \\
& peperangan; kampung - kawasan \\
& kediaman (terdiri daripada sekumpulan \\
& rumah) di luar bandar, desa dan dusun; \\
& tergadai - sudah digadaikan, habis \\
& digadaikan. \\
& (Kamus Dewan Edisi Keempat, 2016) \\
\hline
\end{tabular}


Selaras dengan skop semantik yang terhad pada makna luaran yang diujarkan. Pada tahap ini, baris seloka tersebut hanya boleh ditafsirkan sebagai sesuatu yang konkrit. Analisis berikut menunjukkan cara pembaca membina andaian implikatur dan kesimpulan implikatur. Pembaca akan mengambil kira prosedur pemahaman standard yang dibekalkan dalam konteks seloka PK. Berikut merupakan rumusan implikatur yang dibentuk oleh pembaca:

i. Perlawanan laga ayam dimenangi oleh PK, tetapi kampungnya tergadai.

ii. Sikap terdesak PK untuk melaga ayamnya.

iii. Sikap kebodohan PK menyebabkan kampungnya tergadai.

iv. Sikap tidak fikir panjang.

v. Sepatutnya, PK yang memperoleh hadiah kerana memenangi perlawanan laga ayam dengan sultan.

vi. Hubungan sultan dengan rakyat (PK).

vii. Penipuan sultan untuk mendapatkan kawasan baharu.

viii. Kemenangan dan perjanjian yang melampau dan tidak rasional.

Ini juga merupakan makna sebenar yang ingin disampaikan oleh pengarang Melayu pada zaman dahulu. Rumusan ini jelas menunjukkan bahawa pembaca telah memperoleh kesan kognitif yang tinggi dan merendahkan usaha memproses mereka untuk memahami baris seloka ini. Manifestasi kritikan juga dapat dibentuk dengan baris seloka seperti: "kritikan terhadap sikap seseorang yang membuat keputusan secara melulu", "kritikan terhadap sikap seseorang yang tidak memikirkan keputusan yang diambilnya akan menyebabkan orang lain terkena tempias" dan "kritikan terhadap golongan atasan menggunakan kuasa atau tipu helah untuk memperdayakan orang bawahan". Namun begitu, pencungkilan makna sebenar dalam analisis TR tidak seharusnya disia-siakan. Berdasarkan makna sebenar inilah proses penggabungjalinan dengan konteks semasa (konteks politik tempatan - bagi kajian ini) lebih berwibawa untuk diserap (Daud \& Subet, 2021). Bantuan enjin pencarian Facebook, di lihat mampu menggabungjalinkan baris seloka ini dengan kancah politik tempatan (rujuk Rajah 1).

\section{Rajah 1}

Pertalian Seloka PK dengan Kancah Politik Tempatan

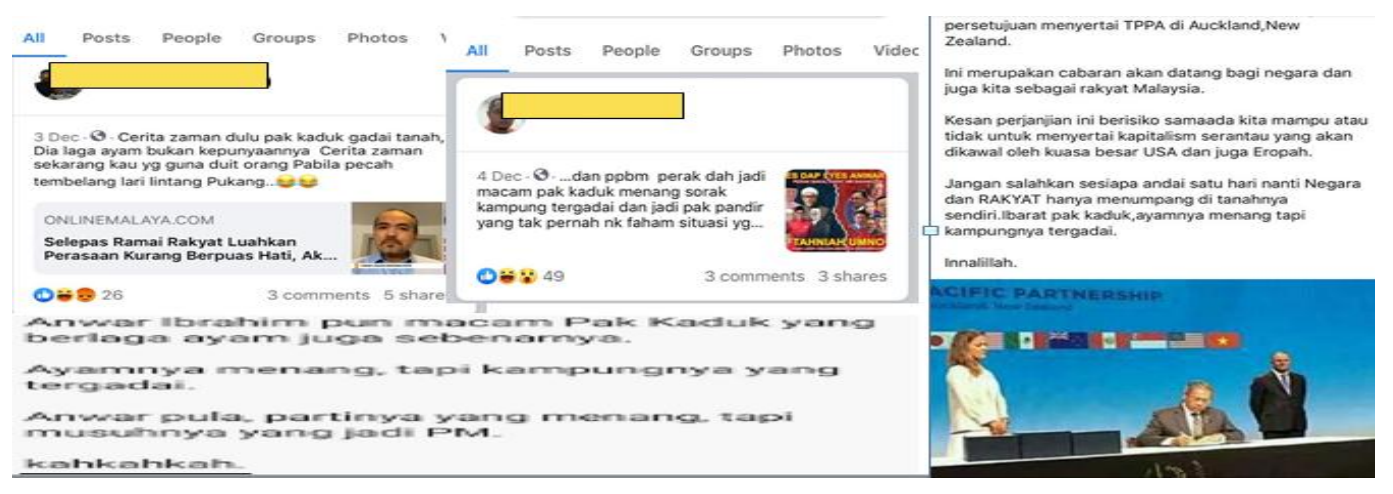


Rajah 1 menunjukkan beberapa contoh pertalian seloka PK dengan kancah politik tempatan yang diperoleh melalui enjin pencarian Facebook. Perkara ini sekali gus membuktikan bahawa masyarakat umum di Malaysia dapat mengaitkan kesan kognitif dalam TR yang dianalisis sebentar tadi dengan proses penggabungan maklumat. Penggabungan maklumat dalam TR akan terjadi apabila andaian awal pembaca dapat digabungkan dengan maklumat baharu penutur. Tugas penggabungan dalam TR ini adalah untuk menghasilkan kesan kognitif yang dapat membantu pembaca memproses mesej penutur dengan lebih mudah dan berwibawa (Sperber \& Wilson, 1986; Subet, 2018; Abdullah \& Daud, 2020). Contohnya, bagi ujaran ini:

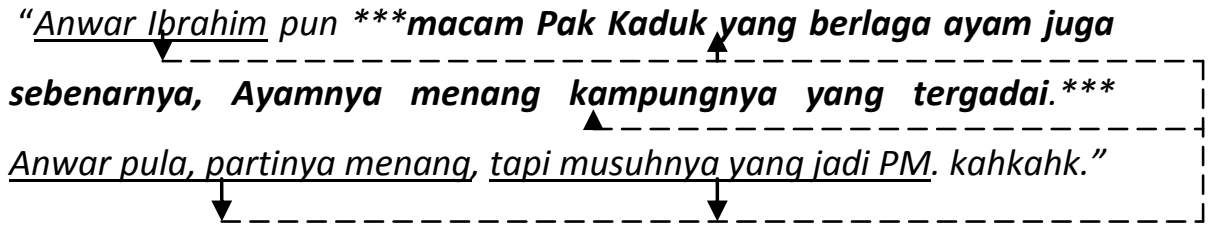

Apabila diteliti dari sudut makna linguistik, pembaca mendapati bahawa makna dalam konteks ujaran ini adalah bersifat implisit. Oleh itu, ad hoc peluasan yang digunakan dalam ujaran ini hasil adalah daripada penggunaan bahasa figuratif "simile" iaitu "macam". Bagi menginterpretasikan kerelevanan ujaran ini dengan baris seloka PK, pembaca seharusnya mempunyai rujukan yang berasal daripada pengetahuan atau pengalaman sedia ada bagi mendapatkan kerelevanan yang optimum. Rangka Rujuk Silang dilakukan bagi memperoleh kesan kognitif berdasarkan ujaran tersebut. Berikut merupakan andaian yang dibentuk oleh pembaca:

i. Anwar Ibrahim (Al) tertipu/terpedaya dengan permainan politik Tun Mahathir (TM).

ii. Strategi Al untuk menggunakan TM memakan diri, kerana TM lebih bijak memanipulasi keadaan.

iii. Al kurang sokongan dalam Pakatan Harapan (PH) berbanding TM.

Andaian ini terbentuk oleh pembaca berdasarkan anteseden "Anwar pula, partinya menang, tapi musuhnya yang jadi $\mathrm{PM}^{\prime}$. Untuk meningkatkan kesan kognitif dan merendahkan usaha memproses pembaca, maka konteks dalam TR turut mengambil kira maklumat sejarah (Subet, 2018). Dengan mengambil kira konteks sejarah iaitu hubungan Al dan TM, Al dikatakan pengkritik TM yang lantang. Al menuduh parti politik pimpinan TM merancang untuk menjatuhkan gabungan pemerintah semasa dan membentuk pakatan baharu bagi menafikan peluang Al sebagai Perdana Menteri (Reuters, 2020). Di sebabkan hubungan dingin antara TM dan Al seperti perselisihan faham dan pemecatan Al pada tahun 1998 semasa krisis kewangan Asia. Al mula menubuhkan gerakan Reformasi dan Parti Keadilan Rakyat (PKR). Namun begitu, pada tahun 1999 dan 2015 Al dipenjarakan kerana disabitkan kesalahan rasuah, liwat dan tuduhan ini dipercayai bermotifkan politik (Reuters, 2020). Tambah Reuters (2020), TM telah membentuk parti baharu (BERSATU) dan menyertai PH. Tahun 2018 pula, TM mengetuai PH dan memenangi Pilihan Raya Umum Ke-14 (PRU-14). Dengan 
kemenangan ini, TM telah mendapatkan pengampunan diraja dan Al dibebaskan. Berpandukan manifestasi kritikan yang dicerna melalui baris seloka PK iaitu "kritikan terhadap golongan atasan menggunakan kuasa atau tipu helah untuk memperdayakan orang bawahan" dapat digabung jalinkan dengan maklumat baharu iaitu konteks politik tempatan. Contohnya isu penyerahan kuasa TM (golongan atasan) sebagai PM, kepada Al (golongan bawahan). Meskipun, Al adalah presiden PKR, tetapi kuasa TM sebagai PM adalah lebih tinggi daripadanya. Hajat Al untuk menjadi PM tidak dapat dipenuhi sekali lagi apabila berlakunya peristiwa "langkah Sheraton".

\section{Kesimpulan}

Kajian ini telah membuktikan bahawa, makna sebenar baris seloka PK yang dicerna melalui TR dapat diperluas dengan konteks politik semasa. Jadi, adalah membazir bagi pengkaji sastera rakyat yang menganalisis data kajian mereka pada peringkat permukaan sahaja. Kajian ini adalah kajian alternatif yang baharu dan rujukan pengkaji akan datang supaya menganalisis sastera rakyat berpandukan perspektif "multidisiplin".

\section{Rujukan}

Abdullah, N. A., \& Daud, M. Z. (2020). Pemaknaan semula sinonim leksikal "nepotisme" berteraskan data korpus: Analisis pragmatik. LSP International Journal, 7(1), 6179.

Ahmad, H., \& Osman, M. T. (2007). Cerita jenaka Melayu. Yayasan Karyawan.

Daud, M. Z., \& Subet, M. F. (2021). Naratif Puteri Santubung dan Puteri Sejinjang mempertalikan politik tempatan: Analisis pragmatik. Issues in Language Studies, 10(1), 110-130.

Ismail, M. S., Bakar, R. A., \& Effendy, N. R. N. M. (2018). Cerita jenaka Melayu suatu manifestasi watak dan perwatakan positif. Jurnal Melayu Sedunia, 1(1), 296329.

Jabar, N. A. (2019). Keunggulan ikon membawa teladan dalam seloka Melayu. Jurnal Antarabangsa Persuratan Melayu, 7(1), 172-191.

Jabar, N. A., \& Ghazali, M. F. (2021). Komunikasi bahasa sindiran dalam Seloka Pak Pandir dan Pak Kaduk. Jurnal Komunikasi, 37(1), 364-378.

Kamus Dewan Edisi Keempat. (2016). Dewan Bahasa dan Pustaka.

Reuters, M. (2020, February 24). Kronologi hubungan Mahathir-Anwar. Harian Metro Online. https://www.hmetro.com.my/mutakhir/2020/02/547870/kronologi-hu bungan-mahathir-anwar

Shaari, R. (1991). Lukisan zaman. Penerbit Fajar Bakti Sdn. Bhd.

Sperber, D., \& Wilson, D. (1986). Relevance: Communication and cognition. Blackwell Publishers.

Subet, M. F. (2018). Analisis teori relevans dalam metafora. Jurnal Bahasa, 18(1), 159188.

Winstedt, R. O. (1969). A history of classical Malay literature. Oxford University Press. 